ARTIGO

DEREVISÃO

\title{
Conseqüências do exercício para o metabolismo da glutamina e função imune
}

\author{
Jair Rodrigues Garcia Júnior ${ }^{1}$, Tânia Cristina Pithon-Curi ${ }^{1,2}$ e Rui Curi ${ }^{1}$
}

\section{RESUMO}

Para o atleta, o objetivo do treinamento é aperfeiçoar sua capacidade física para obtenção do melhor desempenho em competições. Isso o leva a procurar os mais novos e eficientes métodos de treinamento. Um aspecto importante do programa de treinamento é o período de recuperação entre as sessões de exercícios, imprescindível para que ocorram as adaptações fisiológicas, como as alterações morfológicas e a supercompensação das reservas energéticas. A liberação de glutamina pelos músculos esqueléticos é aumentada durante o exercício. Como consequiência, o conteúdo muscular de glutamina diminui após um exercício extenuante. Este aminoácido, entretanto, é muito importante para a funcionalidade dos leucócitos (linfócitos, macrófagos e neutrófilos). Portanto, após um exercício intenso, a concentração plasmática de glutamina diminui, suprimindo a função imune e tornando o indivíduo mais suscetível a infecções respiratórias. Nesta revisão são discutidas as implicações do exercício sobre o metabolismo dos músculos esqueléticos e leucócitos.

Palavras-chave: Exercício. Função imune. Glutamina. Leucócitos. Infecção.

\section{ABSTRACT}

\section{Consequences of exercise for glutamine metabolism and immune function}

The purpose of training for the athletes is to improve physical capacity in order to achieve the best performance in competitions. For this reason, they constantly look for updated training methods. One important aspect in a training program is the rest period between exercise sessions,

1. Departamento de Fisiologia e Biofísica, Instituto de Ciências Biomédicas, USP, São Paulo, SP.

2. Universidade Camilo Castelo Branco, São Paulo, SP.

Endereço para correspondência:

Jair Rodrigues Garcia Júnior

Av. Prof. Lineu Prestes, 1.524, sala 129

Cidade Universitária

05508-900 - São Paulo, SP

E-mail: jgjunior@fisio.icb.usp.br

Rev Bras Med Esporte - Vol. 6, № 3 - Mai/Jun, 2000 which is important to promote physiological adaptations such as morphological alterations and fuel store overcompensation. The release of glutamine by skeletal muscles is increased during exercise activities. As a consequence, the content of glutamine in the muscle decreases after a strenuous exercise session. This amino acid, however, plays an important role in leukocyte functioning (lymphocytes, macrophages, and neutrophils). Therefore, after heavy and intense exercising, plasma glutamine levels decrease, impairing immune function and leading the subject to become more susceptible to respiratory infections. In this review, the implications of exercise on skeletal muscles and leukocytes metabolism are discussed.

Key words: Exercise. Immune function. Glutamine. Leukocytes. Infection.

\section{INTRODUÇÃO}

A busca constante por um melhor desempenho é o objetivo principal de todos os atletas, independentemente do esporte praticado. Esse objetivo é alcançado somente com a soma de vários fatores, mas principalmente pela escolha criteriosa dos métodos de treinamento. Apesar da evolução desses métodos e das pesquisas aplicadas em áreas correlatas que contribuem significativamente para melhorar o desempenho, não é possível minimizar o papel de três variáveis que constituem a base de qualquer programa de treinamento: intensidade, freqüência e duração do exercício.

Essas variáveis são fundamentais para o aprimoramento da capacidade física, porém a ansiedade por melhor desempenho, por vezes, faz com que essas sejam utilizadas em excesso. Este fato, aliado a períodos de recuperação insuficientes, resultam em uma condição conhecida como síndrome do excesso de treinamento (overtraining).

Tal estado é denominado de síndrome devido às várias alterações que acarreta, comprometendo desde a capacidade de treinamento e desempenho em competições, até aspectos fisiológicos e emocionais ${ }^{1,2}$. Dentre as alterações fisiológicas, deve-se incluir a função imune.

É do comprometimento do sistema de defesa relacionado com a atividade física que trataremos nesta revisão. Se- 
rão mostrados o metabolismo e a funcionalidade das células do sistema imune e sua relação com o metabolismo dos músculos esqueléticos, tendo como elo o aminoácido glutamina.

\section{CÉLULAS DO SISTEMA IMUNE E DA RESPOSTA INFLAMATÓRIA}

Linfócitos, macrófagos e neutrófilos desempenham um papel central na resposta imune e inflamatória. Linfócitos são células circulantes, têm sua origem nos tecidos linfóides primários (timo e medula óssea), podendo migrar para os órgãos linfóides secundários (baço, linfonodos e placas de Peyer). Encontram-se em estado quiescente até serem estimulados a proliferar, por exemplo, durante uma infecção por vírus ou bactérias. Os macrófagos podem diferir em suas características bioquímicas, estruturais e funcionais, dependendo do estado de diferenciação, do microambiente e de sua localização no organismo. Em função de sua localização, recebem diferentes denominações: do sistema nervoso central (microglia), fixos no fígado (células de Kupffer), da epiderme (células de Langerhans), do osso (osteoblastos) e os macrófagos livres do espaço alveolar e cavidades serosas ${ }^{3}$. Entretanto, os macrófagos, independentemente de sua localização, compartilham de algumas das propriedades gerais que os tornam semelhantes entre si, como propriedades de espraiamento, de fagocitose e fungicida, bactericida e tumoricida.

Neutrófilos constituem cerca de $60 \%$ dos leucócitos circulantes em seres humanos adultos e são as primeiras células de defesa na resposta inflamatória aguda. Microrganismos fagocitados, recobertos ou não com complemento ou anticorpo específico, são mortos por proteínas citotóxicas derivadas dos grânulos citoplasmáticos e por uma combinação de espécies reativas de oxigênio geradas pelo neutrófilo ${ }^{4}$.

Apesar da inquestionável importância dessas células na resposta imune e inflamatória, relativamente pouco se sabia sobre o metabolismo e sua implicação para as diferentes funções desses tipos celulares. Na década de 80, o grupo do Prof. Eric Newsholme determinou que macrófagos e linfócitos utilizam glutamina em altas taxas ${ }^{5-7}$ e, recentemente, no nosso laboratório, foi verificada pela primeira vez a utilização de glutamina também por neutrófilos ${ }^{8,9}$.

\section{METABOLISMO E FUNCIONALIDADE DOS LEUCÓCITOS}

\section{Linfócitos}

Os linfócitos são células circulares pequenas $(6-10 \mu \mathrm{m}$ de diâmetro), com alta razão núcleo/citoplasma. Estes têm origem nos tecidos linfóides primários (timo e medula ós- sea) podendo migrar para órgãos linfóides secundários (baço, linfonodos, placa de Peyer). Os linfócitos teciduais estão em equilíbrio dinâmico com o sangue circulante. Essas células são subdivididas de acordo com os marcadores de superfície, reações a estímulos, origem e sobrevida. De acordo com sua origem, são classificados em linfócitos T e B. O linfócito B atinge a maturidade na medula óssea e está relacionado com a imunidade humoral, apresenta imunoglobulinas na superfície; quando ativado por antígeno específico, prolifera por mitose e se diferencia em plasmócito, secretando, assim, grande quantidade de anticorpos. Algumas dessas células também originam os linfócitos B da memória imunológica. Essas, por sua vez, mantêm a memória da exposição anterior ao antígeno e respondem rapidamente após uma reexposição ao mesmo antígeno ${ }^{4}$.

Os linfócitos T são os mais numerosos do sangue. Possuem diferenciação e maturação intratímica, não sintetizam quantidades detectáveis de imunoglobulinas, mas atuam como reguladores da resposta imunitária celular. Integra a população de linfócitos $\mathrm{T}$ uma série de subtipos celulares com funções específicas na resposta imunitária, entre esses as células citotóxicas (Tc), auxiliares ou helper (Th) e supressoras (Ts).

\section{Macrófagos}

Macrófagos são células mononucleares que se diferenciam a partir de monócitos. Seu tamanho varia entre 25 e $50 \mu \mathrm{m}$ de diâmetro, possuem núcleo irregular e excentricamente posicionado, com um ou dois nucléolos e cromatina dispersa. Essas células apresentam complexo de Golgi bem desenvolvido, número variável de vesículas de endocitose e grande número de mitocôndrias. A superfície da membrana apresenta-se irregular, com microvilos, e o citoesqueleto é bem desenvolvido, rodeando o núcleo e estendendo-se até a periferia ${ }^{10}$. Essas características ultra-estruturais podem estar modificadas em diferentes condições fisiológicas e patológicas. Macrófagos ativados apresentam superfície mais irregular, grandes vacúolos citoplasmáticos e número aumentado de lisossomos secundários em relação às células quiescentes.

Uma vez nos tecidos, os macrófagos em geral não retornam à circulação, podendo sobreviver por vários meses. Esses são chamados de macrófagos residentes ${ }^{3}$. Os macrófagos residentes estão presentes em órgãos ou tecidos não inflamatórios e secretam lisozima, proteinases neutras e ácidas e espécies reativas do oxigênio, possuindo pequena capacidade microbicida e fungicida. Uma vez ativados, aumentam a secreção dessas substâncias e liberam também uma variedade de proteinases e hidrolases neutras, componentes do sistema complemento, fatores de coagulação, arginase e lisozima.

Rev Bras Med Esporte - Vol. 6, № 3 - Mai/Jun, 2000 
Linfócitos e fagócitos mononucleares agem em conjunto para responder rapidamente na eliminação de antígenos estranhos, regulando a resposta após a eliminação do antígeno. Entretanto, essas células respondem rapidamente a qualquer alteração do sistema imunitário, mas para isso aumentam a demanda metabólica e a taxa de utilização de glutamina.

Os macrófagos apresentam taxas elevadas de utilização de glicose e glutamina ${ }^{3}$, à semelhança de células de divisão rápida, tais como enterócitos, linfócitos e células tumorais. Nos macrófagos, que não proliferam, a glutamina desempenha papel importante na produção de citocinas ${ }^{11}$.

Linfócitos e macrófagos utilizam ativamente glicose e glutamina, porém esses substratos são apenas parcialmente oxidados, sendo a glicose convertida principalmente a lactato e a glutamina, a glutamato, aspartato e lactato $^{12}$. A glicose e a glutamina, para ser oxidadas, devem ser convertidas inicialmente a piruvato, que é descarboxilado no ciclo de Krebs. Dessa forma, o piruvato é o metabólito comum da oxidação parcial de glicose e glutamina em linfócitos e macrófagos ${ }^{7}$.

Sabe-se que, em cultura, macrófagos utilizam ativamente aminoácidos ricos em grupamentos nitrogenados, como glutamina e arginina ${ }^{13}$. Isto indica que o nitrogênio necessário para a síntese de novos aminoácidos e proteínas pode vir da glutamina e arginina extracelulares. Além disso, nessas células, a produção de interleucina- 8 depende da presença de glutamina no meio ${ }^{13}$. Em linfócitos de humanos e de ratos, esse aminoácido é importante para a proliferação ${ }^{12,14,15}$.

\section{Neutrófilos}

Cerca de 100 bilhões de neutrófilos circulam diariamente em um indivíduo de $70 \mathrm{~kg}$, sob condições fisiológicas, número que pode aumentar até dez vezes durante uma infecção aguda ${ }^{16}$, chegando a aproximadamente $5 \times 10^{11}$ células ${ }^{17}$.

Em humanos, os neutrófilos se originam de células primordiais pluripotenciais da medula óssea (que também dão origem aos monócitos, bem como a alguns linfócitos e plaquetas). Após sua formação, cerca de $90 \%$ da população de neutrófilos mantém-se na medula óssea. O restante encontra-se distribuído entre a circulação e o endotélio vascular, onde permanece como população marginal. Este compartimento compreende células retidas pela rede capilar, excluídas temporariamente da circulação por vasoconstrição ou, especialmente nos pulmões, por adesão ao endotélio vascular. Quando liberados da medula óssea, a sobrevida dos neutrófilos é normalmente de oito horas no sangue e de mais de quatro a cinco dias nos tecidos.
Os neutrófilos apresentam um núcleo multilobulado, com cromatina densamente compactada, que dá origem ao termo polimorfonuclear, não apresentam nucléolo, o aparelho de Golgi é pequeno e, quando os neutrófilos estão maduros, variam em tamanho de 10 a $15 \mathrm{~mm}$ de diâmetro.

Os neutrófilos são atraídos quimiotaxicamente por células secretoras (mastócitos e basófilos), bactérias e outros corpos estranhos para as áreas de inflamação. Microrganismos fagocitados, recobertos ou não com complemento ou anticorpo específico, são mortos por proteínas citotóxicas derivadas dos grânulos citoplasmáticos e por uma combinação de espécies reativas de oxigênio ${ }^{4}$. Lloyd e Oppenheim ${ }^{18}$ demonstraram que essas células também participam na síntese e liberação de citocinas (interleucinas- 1 e 6 , fator de necrose tumoral), que modulam os efeitos de linfócitos T e B. Portanto, os neutrófilos apresentam uma função eferente (fagocitose e desgranulação) e outra aferente (liberação de citocinas imunomodulatórias) ligadas às respostas inflamatória e imune.

As espécies reativas de oxigênio geradas pelos neutrófilos, assim como nos macrófagos, desempenham um papel importante como oxidantes microbicidas, bem como mediadores da inflamação e da lesão tecidual. Uma vez estimulados, a maior parte do oxigênio consumida por neutrófilos é convertida em ânion superóxido pela NADPH oxidase.

O ânion superóxido produzido sob estímulo em neutrófilos é rapidamente convertido em peróxido de hidrogênio e radical hidroxil ${ }^{19}$, que contribuem para a atividade microbicida dentro do fagossomo e no meio extracelular ${ }^{20}$.

$\mathrm{O}$ aumento do consumo de glicose por neutrófilos e macrófagos está relacionado com o processo de endocitose e a geração de espécies reativas de oxigênio ${ }^{4,21-24}$. Contudo, a glicose não é o único metabólito energético utilizado por essas células, pois recentemente demonstramos que neutrófilos também utilizam glutamina9.

A taxa de utilização de glutamina por neutrófilos, linfócitos e macrófagos é similar ou até mesmo maior do que a de glicose. Com base nos produtos finais do metabolismo e atividade máxima das enzimas estudadas, pode-se concluir que a glutamina é utilizada por vias similares, mas não idênticas, em macrófagos, linfócitos e neutrófilos ${ }^{25,26}$. Alta taxa de utilização de glutamina e oxidação somente parcial são também características de enterócitos, fibroblastos e células tumorais ${ }^{27-30}$

Em estudos recentes, realizados no nosso laboratório ${ }^{31}$, verificou-se que em neutrófilos de ratos incubados por uma hora, a adrenalina inibe a produção de ânion superóxido induzida por PMA na presença de glicose, mas esta inibição é parcial na presença de glutamina. O efeito inibitório da adrenalina sobre a geração de ânion superóxido por neu- 
trófilos pode ter ocorrido devido à baixa produção de NADPH na via das pentoses. Na presença de adrenalina, os neutrófilos desviariam o fluxo de glicose da via das pentoses para a produção de lactato. Por outro lado, a glutamina aumenta a produção de agentes redutores (NADH e NADPH) no ciclo de Krebs e, neste caso, reduz o efeito inibitório de adrenalina sobre a produção de ânion superóxido. Portanto, a glutamina pode ter uma papel importante na regulação da produção de ânion superóxido. Assim, altas taxas de utilização de glutamina proporcionariam bases metabólicas apropriadas para a produção das espécies reativas de oxigênio por neutrófilos, mantendo sua capacidade citolítica.

\section{VIAS DE SÍNTESE E DEGRADAÇÃO DA GLUTAMINA}

Mais da metade da glutamina consumida na dieta e absorvida é utilizada pelas próprias células intestinais que, por se renovarem rapidamente (poucos dias), necessitam sintetizar constantemente compostos estruturais, principalmente a partir da glicose e desse aminoácido ${ }^{32}$. Dessa forma, a maior proporção da glutamina circulante (concentração aproximada de $0,6 \mathrm{mmol} / \mathrm{L}$ ) é proveniente dos músculos esqueléticos, que sintetizam e exportam glutamina e alanina para a circulação, em especial durante situações de catabolismo intenso, como no jejum prolongado e exercício.

A síntese e a hidrólise de glutamina em tecidos de mamíferos foram primeiramente descritas por Krebs em $1935^{33}$. A síntese de glutamina ocorre preferencialmente no músculo esquelético, fígado, tecido adiposo e cérebro, enquanto a hidrólise ocorre nos rins, linfonodos, macrófagos, trato gastrintestinal e tecido adiposo ${ }^{34-36}$.

A via mais importante para a síntese da glutamina utiliza a metade direita do ciclo de Krebs, que compreende desde o citrato (formado a partir de acetil-CoA e oxaloacetato) até o 2-oxoglutarato (figura 1). Esse último é um oxoácido e pode ser transaminado com os aminoácidos de cadeia ramificada, receber um grupo amina e formar glutamato. Por sua vez, o glutamato pode formar glutamina ao receber outro grupo amina, seja de outro aminoácido ou da reação de desaminação do monofosfato de adenosina (AMP) em monofosfato de inositol (IMP) na via das purinas (figura 2).

A glutamina é o aminoácido livre mais abundante nos músculos esqueléticos, tendo uma concentração normal de 20mmol/L. Exercícios de intensidade moderada (quase intensa) depletam os estoques musculares de glicogênio e demandam elevado metabolismo dos aminoácidos de cadeia ramificada ${ }^{37}$. A concentração de glutamina muscular então é aumentada nos primeiros momentos desse tipo de

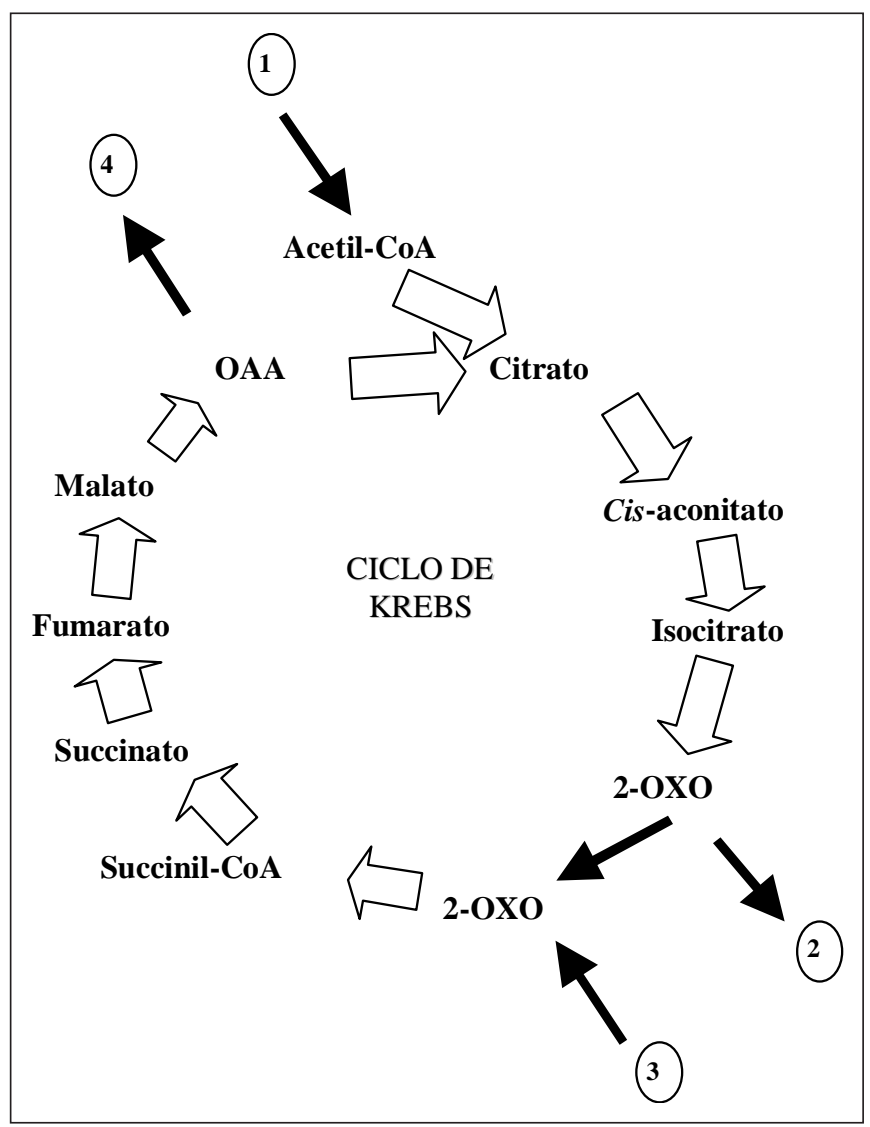

Fig. 1 - Esquema simplificado do ciclo de Krebs mostrando sua divisão em duas partes. A metade direita (do citrato até 2-oxoglutarato) é importante para síntese da glutamina nos músculos esqueléticos e a metade esquerda (do 2-oxoglutarato até oxaloacetato) é importante para a utilização da glutamina nos leucócitos. Os substratos utilizados ou produzidos de acordo com os números são: 1) utilização de glicose, ácidos graxos ou aminoácidos (leucina); 2) síntese de glutamato e glutamina; 3) utilização de glutamato e glutamina; 4) síntese de aspartato. Abreviaturas: OAA: oxaloacetato, 2-OXO: 2-oxoglutarato.

exercício, porém volta ao normal em seguida devido a sua exportação para a circulação. Nesta, a glutamina tem com principais destinos o fígado e os rins, onde é utilizada no processo de gliconeogênese. Alguns estudos demonstraram que a glutamina é o principal precursor para a gliconeogênese hepática ${ }^{38,39}$. Outros destinos da glutamina são as células intestinais e, principalmente, as células do sistema imune durante o exercício, quando ocorre leucocitose.

\section{METABOLISMO MUSCULAR DURANTE O EXERCÍCIO}

A molécula de trifosfato de adenosina (ATP), por meio da quebra das ligações de alta energia entre seus fosfatos, fornece energia para a contração muscular, porém sua concentração nos músculos é pequena, suficiente para poucos 


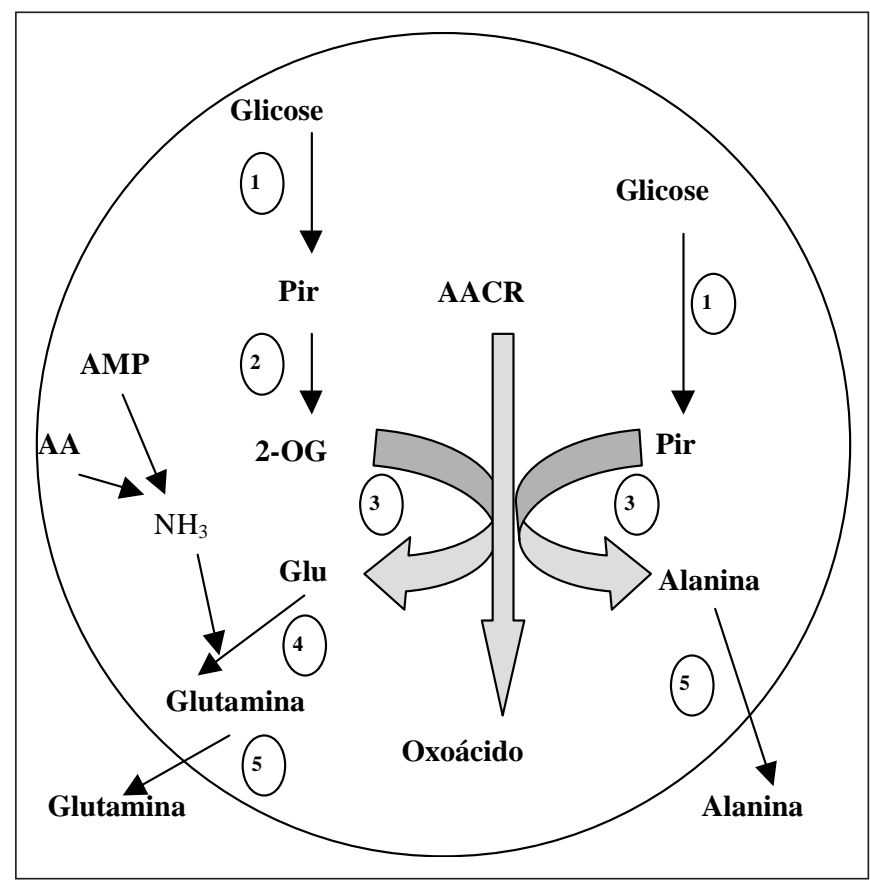

Fig. 2 - Metabolismo dos aminoácidos de cadeia ramificada (AACR) $e$ formação de glutamina e alanina nos músculos esqueléticos. As reações indicadas pelos números são: 1) glicólise, 2) formação do acetilCoA e primeira metade do ciclo de Krebs, 3) transaminações, 4) enzima glutamina sintetase, 5) transporte dos aminoácidos para a circulação. Abreviaturas: AA: aminoácidos, AMP: adenosina-monofosfato, Glu: glutamato, 2-OG: 2-oxoglutarato, Pir: piruvato.

segundos de contrações musculares apenas ${ }^{40}$. Por isso, existem três sistemas muito eficientes para a ressíntese constante das moléculas de ATP durante o exercício. A predominância de um ou outro sistema é determinada pela intensidade e duração do exercício.

$\mathrm{O}$ primeiro sistema pode ser denominado de creatinafosfato (CP) devido à utilização da energia dessa ligação fosfato para a ressíntese do ATP. Esse sistema atua imediatamente após a utilização do ATP armazenado, mas também é suficiente para apenas poucos segundos adicionais de contrações. É acionado no início de qualquer atividade física.

O segundo sistema é a glicólise anaeróbia e decorre da quebra da glicose até a formação de ácido lático com ressíntese de ATP independente de $\mathrm{O}_{2}$. É um sistema muito potente, ou seja, com capacidade elevada de ressíntese de ATP em curtos períodos; por isso, é utilizado durante exercícios intensos com duração máxima de poucos minutos, já que a diminuição do $\mathrm{pH}$ provocada pelo ácido lático inibe algumas enzimas dessa via e impede a continuação do processo $^{41}$.

O último sistema é a fosforilação oxidativa. Nesse, a ressíntese de ATP ocorre durante o transporte de elétrons, sen- do o $\mathrm{O}_{2} \mathrm{o}$ aceitante final dos mesmos. Esse é considerado o sistema mais eficiente em quantidade de ATP ressintetizada, porém consegue atender plenamente somente as demandas de exercícios de intensidade moderada, quando a oferta de oxigênio é suficiente. Além de sintetizar mais ATP que os outros sistemas, essa via apresenta outra vantagem, que é a capacidade de gerar energia a partir de três substratos energéticos: glicose, ácidos graxos e aminoácidos ${ }^{42}$. De qualquer forma, tanto em exercícios moderados como intensos, o principal substrato energético utilizado é o glicogênio e a duração do exercício, até que haja diminuição do desempenho ou se atinja a exaustão, é determinada pelos seus estoques nos músculos solicitados ${ }^{43}$.

No período de recuperação ocorre um processo chamado de débito de $\mathrm{O}_{2}$, no qual o metabolismo continua elevado durante várias horas, porém em constante declínio, podendo ser dividido em três fases: 1) fase rápida, com duração de poucos minutos, suficiente para a repleção dos fosfagenos (ATP e CP) e reoxigenação da mioglobina e hemoglobina; 2) fase lenta, com duração de aproximadamente uma hora, quando o lactato é convertido a glicose e glicogênio (gliconeogênese hepática); 3) fase ultralenta, com duração de várias horas, em que se propõe que a estimulação dos ciclos de substratos (interconversões de substratos, como proteína $\rightarrow$ aminoácidos $\rightarrow$ proteína, por exemplo) seja o fator responsável pelo débito de $\mathrm{O}_{2}{ }^{41}$. A utilização dos substratos nesse período é determinada pelo consumo de nutrientes. Caso nada seja consumido além de água, o catabolismo de proteínas e a mobilização de ácidos graxos continuam, com esses últimos sendo utilizados como principal substrato. Em havendo consumo de nutrientes, principalmente carboidratos, o anabolismo protéico e a reesterificação dos ácidos graxos são estimulados e a glicose passa a ser utilizada como o principal substrato ${ }^{44}$.

Uma peculiaridade dos músculos esqueléticos em relação ao metabolismo dos aminoácidos é que, ao mesmo tempo que utilizam alguns deles (leucina, isoleucina, valina, glutamato, aspartato e asparagina) para a oxidação ou síntese de intermediários do ciclo de Krebs ${ }^{45}$, sintetizam alanina e glutamina, que são exportados para a circulação, onde tomam destinos diversos ${ }^{40}$. Tanto a alanina quanto a glutamina desempenham um papel muito importante, que é o de carrear a amônia resultante da desaminação de outros aminoácidos para o fígado e rins, evitando que os músculos acumulem esse composto tóxico.

\section{CONCENTRAÇÃO PLASMÁTICA DE GLUTAMINA DURANTE E APÓS O EXERCÍCIO}

O treinamento tem como característica estimular adaptações morfológicas e metabólicas nos músculos esquelé- 


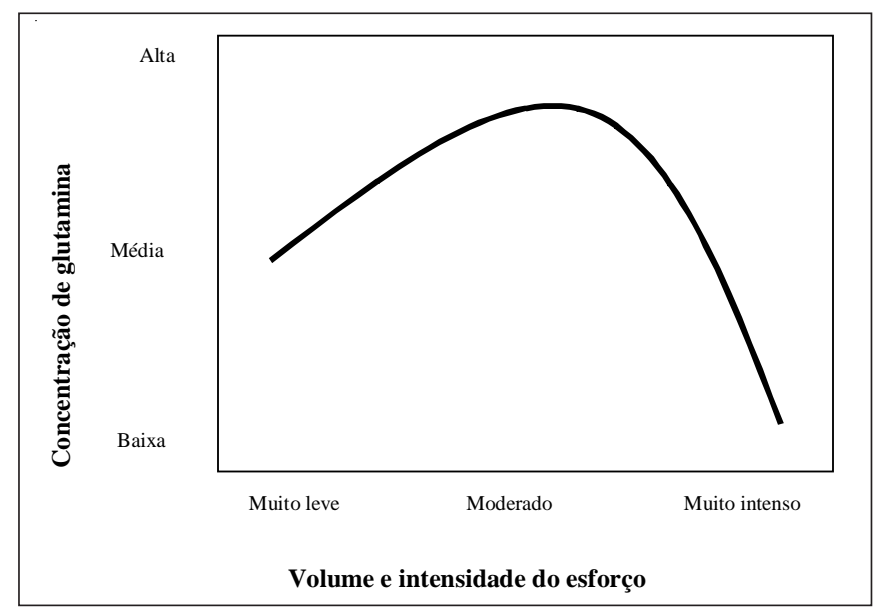

Fig. 3 - Relação sugerida entre a intensidade do esforço e a concentração plasmática de glutamina. A curva em forma de " $J$ " invertido mostra que exercícios moderados aumentam a concentração de glutamina circulante, enquanto exercícios intensos diminuem a concentração desta. Modificado de Rowbottom et al. ${ }^{48}$.

ticos e alterar a mobilização e utilização de substratos energéticos. Tais alterações geralmente trazem benefícios para o desempenho e saúde do atleta; entretanto, podem também interferir no equilíbrio metabólico e endócrino e prejudicar alguns sistemas.

O supertreinamento, particularmente, constitui-se numa situação extrema para o atleta, pois é caracterizado pela incapacidade de recuperação adequada após sucessivas seções de treinamento. A sensação de fadiga persiste mesmo após os períodos regulares de recuperação e acarreta alterações emocionais, comportamentais e físicas ${ }^{1,2,46}$. Essa situação é prejudicial ao atleta não apenas pela impossibilidade de continuação do programa de treinamento e pela queda do desempenho nas competições, mas também pelas conseqüências fisiológicas relacionadas à sua própria saúde.

Estudos têm relacionado o excesso de treinamento, treinamento intenso e também exercícios de longa duração com a diminuição da resposta imune ${ }^{47-49}$. Essa condição decorre de alterações hormonais ${ }^{50-52}$ e do metabolismo dos músculos esqueléticos e das células envolvidas no mecanismo de defesa ${ }^{53-55}$.

A diminuição da concentração plasmática de glutamina tem sido mencionada por diversos autores como o fator que reduz a funcionalidade dos leucócitos, deixando o atleta mais vulnerável a infecções ${ }^{51,54,56,57}$.

Como já visto anteriormente, os músculos esqueléticos são a principal fonte da glutamina circulante, que por sua vez é imprescindível para o metabolismo e funcionalidade dos leucócitos. Em humanos, a capacidade dos músculos esqueléticos de liberar glutamina é de pelo menos $42 \mathrm{mmol} /$ $\mathrm{h}^{58}$, enquanto que o consumo total de glutamina por todos os linfócitos do organismo é de aproximadamente $24 \mathrm{mmol} /$ h. Esses dados indicam que a demanda de glutamina pelo linfócito pode ser suprida completamente pelo músculo esquelético. Entretanto, se houver aumento na taxa de consumo desse aminoácido ou até mesmo se a produção e liberação pelo músculo estiverem excessivamente diminuídas, poderá haver comprometimento da função imune. Nessas condições, a glutamina é considerada um aminoácido "condicionalmente essencial".

O efeito do exercício sobre a concentração plasmática de glutamina (ou produção de glutamina pelos músculos esqueléticos) varia de acordo com a intensidade do esforço $^{48}$. Em exercícios de baixa intensidade, a concentração plasmática de glutamina não se altera, enquanto em esforços moderados aumenta e em atividades intensas há diminuição. Graficamente, essa variação pode ser representada por uma curva em forma de "J" invertido (figura 3).

Em estudos de laboratório com exercícios controlados e no campo com coleta de amostras em competições tem sido demonstrada diminuição da concentração plasmática de glutamina durante ou mesmo após o término do esforço. Já no início dos anos 80, Rennie et al. ${ }^{59}$ determinaram a concentração plasmática de diversos aminoácidos após um exercício de 225 minutos de duração a $50 \%$ do $\dot{\mathrm{VO}}_{2 \text { máx. }}$ e observaram que a diminuição da concentração de glutamina circulante (de 0,557 para $0,470 \mathrm{mmol} / \mathrm{L}$ ) foi a mais acentuada entre todos os aminoácidos analisados. Sahlin et al. ${ }^{60}$ mostraram diminuição do conteúdo de glutamina nos músculos com o decorrer do exercício ( $75 \%$ do $\mathrm{V}_{2}$ máx.), provavelmente devido ao aumento de aproximadamente $125 \%$ do efluxo desse aminoácido dos músculos.

Competições tais como corridas de maratona, devido à duração e à intensidade do esforço empregado pelos atletas, parecem ser especialmente propícias em demonstrar essa relação do exercício com a concentração de glutamina no plasma e no músculo esquelético. Parry-Billings et $a l .{ }^{53}$ estudaram corredores treinados após o final de uma prova de maratona e observaram diminuição significativa na concentração plasmática de glutamina (de 0,592 para $0,495 \mathrm{mmol} / \mathrm{L}$ ) e dos aminoácidos de cadeia ramificada (de 0,489 para $0,404 \mathrm{mmol} / \mathrm{L}$ ). Resultados semelhantes foram encontrados por Castell et al. ${ }^{61}$ também após uma prova de maratona. Nesse caso, houve diminuição da concentração de glutamina (de 0,571 para $0,462 \mathrm{mmol} / \mathrm{L}$ ) e dos aminoácidos de cadeia ramificada (de 0,487 para $0,368 \mathrm{mmol} / \mathrm{L}$ ), e o restabelecimento da condição pré-esforço ocorreu somente após $16 \mathrm{~h}$ de recuperação.

Keast et al. ${ }^{55}$ relacionaram a intensidade do exercício com a concentração plasmática de glutamina e encontraram uma correlação inversa. Esses autores verificaram que a con- 
centração plasmática de glutamina é reduzida em atletas submetidos a um treinamento intenso durante dez dias, e verificaram que esta permaneceu menor nos seis dias seguintes ao término do período de treinamento.

Walsh et al..$^{57}$ observaram que um único exercício intermitente e intenso ( $100 \%$ do $\dot{\mathrm{VO}}_{2 \text { máx. }}$ é suficiente para provocar uma diminuição significativa da concentração plasmática de glutamina até $5 \mathrm{~h}$ após o término do esforço. Sintomaticamente, neste mesmo período, havia um número significativamente maior de leucócitos circulantes.

A hipótese mais provável para explicar a diminuição da concentração plasmática de glutamina em situações de estresse metabólico, como exercícios prolongados e treinamentos intensos, parece ser a de que há aumento significativo da captação de glutamina pelo fígado, rins e intestino, principalmente nos dois primeiros órgãos, para assegurar a síntese de novo de glicose no processo de gliconeogênese e tamponamento da acidose, respectivamente ${ }^{57,62}$. Porém, há a possibilidade das células do sistema imune, devido à leucocitose causada pelo exercício, também contribuírem com uma captação considerável de glutamina do plasma ${ }^{63}$. Outro fator seria a menor liberação de glutamina do músculo esquelético. Isto seria conseqüência da inibição da glutamina sintetase, como já foi demonstrado em casos de exercícios intensos ${ }^{64-65}$. Além disso, a depleção do glicogênio muscular pode ter duas consequiências diretas sobre o processo de síntese de glutamina. Uma conseqüência está relacionada à dependência de esqueletos de carbono para a síntese da glutamina por meio de transaminação com os aminoácidos de cadeia ramificada (ver figura 2) ${ }^{66}$. A outra está relacionada à diminuição da concentração plasmática dos aminoácidos de cadeia ramificada, já que a diminuição do conteúdo de glicogênio ativa o complexo enzimático cetoácido de cadeia ramificada desidrogenase (BCKADh) e leva ao aumento da captação e do consumo desses aminoá$\operatorname{cidos}^{67}$.

\section{SUPLEMENTAÇÃO DE GLUTAMINA}

A importância da suplementação de glutamina vem sendo estudada em processos que envolvem respostas imune e inflamatória. A concentração plasmática de glutamina está diminuída em condições de estresse, tais como em pacientes queimados ${ }^{14}$, durante a septicemia ${ }^{68,69}$, pós-cirurgia ${ }^{53,70,71}$, após exercícios de resistência ${ }^{61,72}$ e no supertreinamento ${ }^{53}$. Além disso, indivíduos submetidos a um período de dez dias de treinamento intenso, com tempo insuficiente de repouso entre as sessões, apresentam redução de $50 \%$ na concentração plasmática de glutamina ${ }^{55}$.

Koyama et al. ${ }^{15}$ também demonstraram a importância da glutamina para a proliferação de linfócitos num estudo no qual compararam o efeito do treinamento e da injeção de metionina sulfoximina (MS), uma droga inibidora da glutamina sintetase. Como esperado, após o treinamento, houve aumento significativo da concentração plasmática de corticosterona e diminuição significativa da capacidade proliferativa dos linfócitos bem como da concentração plasmática de glutamina. Com a administração da droga MS, houve o mesmo efeito de diminuição da concentração plasmática de glutamina e da proliferação de linfócitos sem, no entanto, haver alteração da concentração de corticosterona.

Há evidências de que, em exercícios intensos e prolongados, a ingestão de fluidos contendo glutamina reduz a incidência de infecções no trato respiratório ${ }^{73,74}$.

Outro estudo demonstrou a eficiência de uma suplementação de glutamina em diminuir a incidência de infecções em atletas durante sete dias após exercício prolongado. No grupo placebo, foi observada incidência de infecções em $51 \%$ dos atletas, enquanto no grupo suplementado esta foi de apenas $19 \%^{75}$.

\section{AGRADECIMENTOS}

Os autores são gratos ao constante apoio da FAPESP, CNPq, PRONEX e Conselho Britânico.

\section{REFERÊNCIAS}

1. Budgett R. Overtraining syndrome. Br J Sports Med 1990;24:231-6.

2. Kuipers H. Training and orvertraining: an introduction. Med Sci Sports Exerc 1998;30:1137-9.

3. Gordon S. Biology of the macrophages. J Cell Sci 1986;4:267-86.

4. Stites DP, Terr AL. Basic human immunology. New York: Prentice Hall, 1991.

5. Curi R, Newsholme P, Newsholme EA. Intracellular distribution of some enzymes of the glutamine utilisation pathway in rat lymphocytes. Biochem Biophys Res Commun 1986;138:318-32.

6. Newsholme P, Curi R, Blomstrand E, Gordon S, Newsholme EA. Localization and characterization of glutaminase activity in the murine macrophage. Biochem Soc Trans 1987;16:536.

7. Curi R, Newsholme P, Newsholme EA. Metabolism of pyruvate by isolated rat mesenteric lymphocytes, lymphocyte mitochondria and isolated mouse macrophage. Biochem J 1988;250:383-8.

8. Pithon-Curi TC, Pires de Melo M, de Azevedo RB, Curi R. Glutamine utilisation by rat neutrophils. Characterization of phosphate-dependent glutaminase. Immunology 1996;89:R184.

9. Pithon-Curi TC, Pires de Melo M, de Azevedo R, Zorn TMT, Curi R. Glutamine utilization by rat neutrophils. Presence of phosphate-dependent glutaminase. Am J Physiol 1997;273:C1124-C1129.

10. Dinarello CA. The endogenous pyrogens in host-defense interactions. Hosp Pract 1989;24:111-5.

11. Yaqoob P, Calder P. Cytokine production by human peripheral blood mononuclear cells: differential sensitivity to glutamine availability. Cytokine 1998;10:790-4.

12. Ardawi MSM, Newsholme EA. Glutamine metabolism in lymphocytes of the rat. Biochem J 1983;212:835-42. 
13. Murphy CJ, Newsholme P. Importance of glutamine metabolism in murine macrophages and human monocytes to L-arginine biosynthesis and rates of nitrite or urea production. Clin Sci (Colch) 1998;95:397407.

14. Parry-Billings M, Evans J, Calder PC, Newsholme EA. Does glutamine contribute to immunosuppression after major burns? Lancet 1990;336: 523-5.

15. Koyama K, Kaya M, Tsujita J, Hori S. Effects of decreased plasma glutamine concentrations on peripheral lymphocytes proliferation rats. Eur J Appl Physiol 1998;77:25-31.

16. Lee GR, Bithell TC, Foerster J, Athens JW, Lukens JN. Leukocytes: the phagocytic and immunologic systems. In: Wintrobe's clinical hematology, Philadelphia: Lea Febiger, 1993:223-57.

17. Yang KD, Hill HR. Neutrophil function disorders: pathophysiology, prevention, and therapy. J Pediatr 1991;119:43-54.

18. Lloyd AR, Oppenheim JJ. Poly's lament: the neglected role of the polymorphonuclear neutrophil in the afferent limb of the immune response. Immunol Today 1992;13:169-72.

19. Allen RC. Biochemiexcitation: chemiluminescence and the study of biological oxygenation reactions. In: Adam W, Cilento G, editors Chemical and biological generation of excited states. New York: Academic Press, 1982:309.

20. Pithon-Curi TC, Pires de Melo M, Palanch AC, Miyasaka CK, Curi R. Percentage of phagocytosis, production of $\mathrm{O}_{2}-\mathrm{H}_{2} \mathrm{O}_{2}$ and $\mathrm{NO}$ and antioxidant enzyme activities of rat neutrophils in culture. Cell Biochem Funct 1998;16:43-9.

21. Selvaraj RJ, Sbarra AJ. Relationship of glycolytic and oxidative metabolism to particle entry and destruction in phagocytosing cells. Nature 1966;17:1272-6.

22. Lehrer RI. Effects of colchicine and chloramphenicol on the oxidative metabolism and phagocytic activity of human neutrophils. J Infect Dis 1973;127:40-8.

23. Johnston Jr. RB. Oxigen metabolism and the microbicidal activity of macrophages. FASEB J 1978;37:2756-64.

24. Boregaard N, Herlin T. Energy metabolism of human neutrophils during phagocytosis. J Clin Invest 1982;70:550-7.

25. Curi R, Newsholme P, Pithon-Curi TC, Pires-de-Melo M, Garcia C, Homem-de-Bittencourt Jr. PI, et al. Metabolic fate of glutamine in lymphocytes, macrophages and neutrophils. Braz J Med Biol Res 1999;32: 15-21.

26. Newsholme P, Curi R, Pithon-Curi TC, Murphy CJ, Garcia C, Melo MP. Glutamine metabolism by lymphocytes, macrophages, and neutrophils: its importance in health and disease. J Nutr Biochem 1999;10: 316-24.

27. Hume DA, Weidemann MJ. Role and regulation of glucose metabolism in proliferating cells. J Natl Cancer Inst 1979;62:3-8.

28. Parry-Billings M, Leighton B, Dimitriadis GD, Curi R, Bond J, Bevan $\mathrm{S}$, et al. The effect of tumour bearing on skeletal muscle glutamine metabolism. Int J Biochem 1991;23:933-7.

29. Dos-Santos MA, Rosa R, Curi R, Barbieri DHGP. Effect of protein malnutrition on the glycolytic and glutaminolytic enzyme activity of rat thymus and mesenteric lymph nodes. Braz J Med Biol Res 1997;30: 719-22.

30. Fernandes LC, Curi R. Reversion of Walker 256 tumor cachexia by insulin treatment. Cancer J 1997;4:465-74.

31. Garcia C, Pithon-Curi TC, Firmano ML, Pires-de-Melo M, Newsholme P, Curi R. Effect of adrenaline on glucose and glutamine metabolism and superoxide production by rat neutrophils. Clin Sci (Colch) 1999;96:549-55
32. Souba WW. Intestinal glutamine metabolism and nutrition. J Nutr Biochem 1993;4:2-9.

33. Krebs HA. Metabolism of aminoacids. The synthesis of glutamine from glutamic acid and ammonia, and enzimic hydrolysis of glutamine in animal tissues. Biochem J 1935;29:1951-69.

34. Kowalchuck JM, Curi R, Newsholme EA. Glutamine metabolism in isolated incubated adipocytes of the rat. Biochem J 1988;249:705-8.

35. Curi R, Newsholme EA. The effect of adenine nucleotides on the rate fate of glutamine utilization by incubated mitochondria isolated from rat mesenteric lymph nodes. Mol Cel Biochem 1989;86:71-6.

36. Fryan KN, Khan K, Coppack SW, Elia M. Amino acid metabolism in human subcutaneous adipose tissue in vivo. Clin Sci 1991;80:471-4.

37. Gastmann UAL, Lehmann MJ. Overtraining and the BCAA hypothesis. Med Sci Sports Exerc 1998;30:1173-8.

38. Nurjhan N, Bucci A, Perriello G, Stumvoll M, Dailey G, Bier DM, et al. Glutamine: a major gluconeogenic precursor and vehicle for interorgan carbon transport in man. J Clin Invest 1995;95:272-7.

39. Hankard RG, Haymond MW, Darmaun D. Role of glutamine as a precursor in fasting humans. Diabetes 1997;46:1535-41.

40. Hargreaves M, editor. Exercise metabolism. Champaign: Human Kinetics, 1995.

41. Newsholme EA, Leech AR. Biochemistry for the medical sciences. New York: John Wiley \& Sons, 1983.

42. Henriksson J. Effect of training and nutrition on the development of skeletal muscle. J Sports Sci 1995;13:S25-S30.

43. Newsholme EA, Leech T, Duester G. Keep on running: the science of training and performance. Chichester: John Wiley \& Sons, 1994.

44. MacDonald IA, Webber J. Feeding, fasting and starvation: factors affecting fuel utilization. Proc Nutr Soc 1995;54:267-74.

45. Wagenmakers AJ. Muscle amino acid metabolism at rest and during exercise: role in human physiology and metabolism. Exerc Sport Sci Rev 1998;26:287-314.

46. Eichner ER. Overtraining: consequences and prevention. J Sports Sci 1995;13:S41-S48

47. Sharp NCC, Koutedakis Y. Sport and the overtraining syndrome: immunological aspects. Br Med Bull 1992;48:518-33.

48. Rowbottom DG, Keast D, Goodman C, Morton AR. The haematological, biochemical and immunological profile of athletes suffering from the overtraining syndrome. Eur J Appl Physiol 1995;70:5029.

49. Gabriel HHW, Urhausen A, Valet G, Heidelbach U, Kindermann W. Overtraining and immune system: a prospective longitudinal study in endurance athletes. Med Sci Sports Exerc 1998;30:1151-7.

50. Pedersen BK. Acute, time-limited exercise stress and the immune system: role of stress hormones. In: Maughan RJ, Shirreffs SM, editors. Biochemistry of exercise IX, Aberdeen, Scotland: Human Kinetics, 1996:377-82.

51. Pedersen BK, Bruunsgaard H, Klokker M, Kappel M, MacLean DA, Nielsen HB, et al. Exercise-induced immunomodulation - Possible roles of neuroendocrine and metabolic factors. Int J Sports Med 1997;18(Suppl 1):S2-S7.

52. Nieman DC, Pedersen BK. Exercise and immune function. Recent developments. Sports Med 1999;27:73-80.

53. Parry-Billings M, Budgett R, Koutedakis Y, Blomstrand E, Brooks S, Williams C, et al. Plasma amino acid concentrations in the overtraining syndrome: possible effects on the immune system. Med Sci Sports Exerc 1992;24:1353-8.

54. Newsholme EA. Biochemical mechanisms to explain immunosuppression in well-trained and overtrained athletes. Int J Sports Med 1994;15: S142-S147. 
55. Keast D, Arstein D, Harper W, Fry RW, Morton AR. Depression of plasma glutamine concentration after exercise stress and its possible influence on the immune system. Med J Aus 1995;162:15-8.

56. Mackinnon LT. Immunity in athletes. Int J Sports Med 1997;18(Suppl. 1):S62-S68.

57. Walsh NP, Blannin AK, Clark AM, Cook L, Robson PJ, Gleeson M. The effects of high-intensity intermittent exercise on the plasma concentrations of glutamine and organic acids. Eur J Appl Physiol 1998;77: 434-8.

58. Schröck H, Cha CMJ, Goldstein L. Glutamine release from hindlimb and up-take by kidney in the acutely acidotic rat. Biochem J 1980;188: 557.

59. Rennie MJ, Edwards RHT, Krywawych S, Davies CT, Halliday D, Waterlow JC, et al. Effect of exercise on protein turnover in man. Clin Sci 1981;61:627-39.

60. Sahlin K, Katz A, Broberg S. Tricarboxylic acid cycle intermediates in human muscle during prolonged exercise. Am J Physiol 1990;259: C834-C841.

61. Castell LM, Poortmans JR, Leclercq R, Brasseur M, Duchateau J, Newsholme EA. Some aspects of the acute phase response after a marathon race, and the effects of glutamine supplementation. Eur J Appl Physiol 1997;75:47-53.

62. Walsh NP, Blannin AK, Robson PJ, Glesson M. Glutamine, exercise and immune function. Links and possible mechanisms. Sports Med 1998;26:177-91.

63. Rowbottom DG, Keast D, Morton AR. The emerging role of glutamine as an indicator of exercise stress and overtraining. Sports Med 1996;21: 80-97.

64. Falduto MT, Hickson RC, Young AP. Antagonism by glucocorticoids and exercise on expression of glutamine synthetase in skeletal muscle. FASEB J 1989;3:2623-38.

65. Falduto MT, Young AP, Smyrniotis G, Hickson RC. Reduction of glutamine synthetase mRNA in hypertrophied skeletal muscle. Am J Physiol 1992;262:R1131-R1136.
66. Newsholme EA, Newsholme P, Curi R. The role of citric acid cycle in cells of the immune system and its importance in sepsis, trauma and burns. Biochem Soc Symp 1987;54:145-61.

67. Zanker CL, Swaine IL, Castell LM, Newsholme EA. Responses of plasma glutamine, free tryptophan and branched-chain amino acids to prolonged exercise after a regime designed to reduce muscle glycogen. Eur J Appl Physiol 1997;75:543-8.

68. Milewski PJ, Threlfall CJ, Heath DF, Holbrook JB, Wilford K, Irving $\mathrm{MH}$. Intracellular free amino acids in undernourished patients with and without sepsis. Clin Sci 1982;62:83-91.

69. Roth E, Funovics J, Muhlbacher F, Schemper M, Mauritz W, Sporn P, et al. Metabolic disorders in severe abdominal sepsis: glutamine deficiency in skeletal muscle. Clin Nutr 1982;1:25-41.

70. Powell H, Castell LM, Parry-Billings M, Desborough JP, Hall GM, Newsholme EA. Growth hormone suppression and glutamine flux associated with cardiac surgery. Clin Physiol 1994;14:569-80.

71. Jensen GL, Miller RH, Talabiska DG, Fish J, Gianferante L. A double blind, prospective, randomized study of glutamine-enriched with standard peptide-based feeding in critically ill patients. Am J Clin Nutr 1996;64:615-21.

72. Rohde T, MacLean DA, Hartkopp A, Pedersen BK. The immune system and serum glutamine during a triathlon. Eur J Appl Physiol 1996; 74:428-34.

73. Castell LM, Newsholme EA. The effect of oral glutamine supplementation on athletes after prolonged, exhaustive exercise. Nutrition 1997; 13:738-42.

74. Nieman DC. Imune response to heavy exertion. J Appl Physiol 1997;82: 1385-94.

75. Castell LM, Poortmans JR, Newsholme EA. Does glutamine have a role in reducing infections in athletes? Eur J Appl Physiol 1996;73: 488-90. 